\title{
Rhein Il ou notas sobre a construção da visibilidade da fotografia na arte contemporânea ${ }^{1}$
}

\section{Rhein II or notes about the construction of the visibility of photography within contemporary art}

Fernando do Nascimento Gonçalves

Professor Doutor da Faculdade de Comunicação Social da Universidade do Estado do Rio de Janeiro (UERJ). <goncalvesfernandon@gmail.com>

\section{RESUMO}

O artigo trata do caso da fotografia Rhein II, do artista alemão Andreas Gursky, vendida em um leilão de arte por cerca de quatro milhões de dólares e considerada até recentemente como a fotografia mais cara do mundo. Apoiado metodologicamente na Teoria do Ator-Rede, o texto analisa os processos de construção de sentido e de valor conferido à Rhein II, buscando evidenciar como estes não dizem respeito apenas à arte e seus objetos, mas também à questão da representação no campo das imagens e às mudanças nas funções e nos modelos de produção, circulação e legitimação da fotografia na arte e nos modos de organização de nossa experiência sensível nesse contexto.

Palavras-chave: Fotografia. Arte contemporânea. Produção de sentido.

\begin{abstract}
The paper addresses the case of Rhein II, a photograph by German artist Andreas Gursky, sold in an art auction for about four million dollars and considered until recently as the most expensive photograph in the world. Based methodologically on the NetworkActor Theory, the paper analyzes the processes of construction of the meaning and the value assigned to Rhein II and aims to evince that they set not only the experience of art and of its objects but also draws attention to the issue of representation in the domain of images and to the changes in the functions and patterns of production, circulation and legitimation of the photographic image in art and in the forms of Organization of our aesthetic experience in this context.
\end{abstract}

Keywords: Photography. Contemporary Art. Production of Sense

\section{Introdução}

Este artigo discute as tramas envolvidas na construção da visibilidade da fotografia na arte contemporânea e as mudanças no estatuto do fotográfico nesse contexto. Para tanto, o texto analisa o caso da obra do artista alemão Andreas Gursky, Rhein II, leiloada em 2011 pela Christie's de Nova York pelo maior valor já pago até 2014 por uma imagem fotográfica: quatro milhões e trezentos mil dólares. $\mathrm{O}$ objetivo aqui será menos analisar a obra ou explicar o fenômeno e mais tomá-lo como um problema que aponta para alguns dos aspectos que envolvem a imagem fotográfica no campo da arte hoje e que nos permite considerá-la uma questão de comunicação.

1 Pesquisa financiada pelo CNPq e pela Faperj 
A discussão inscreve-se em uma investigação mais ampla sobre as condições de presença e de legitimação da fotografia na arte contemporânea, das quais os trabalhos de artistas como Andreas Gursky fazem parte. Metodologicamente apoiado na teoria do Ator-Rede ${ }^{1}$, o texto buscou seguir os traços dos processos que construíram a atribuição de sentido e valor de apreciação de Rhein // no mercado para compreender algumas das questões implicadas nas atuais formas de produzir imagens e também de apresentá-las no campo da arte.

Sem desconsiderar seu aspecto de documento e de expressão, ao analisar o caso de Rhein II, interessará observá-lo não precipuamente do ponto de vista da análise da obra, mas do da controvérsia que ela constitui e que se inscreve em redes de relações que organizam sua "fatura". São essas redes que parecem conferir-Ihe sentido e valor e que apontam, ao mesmo tempo, para algumas das mudanças por que vem passando a fotografia na atualidade, particularmente no campo da arte. Ao texto interessará, então, observar como diversos elementos participam dessa construção de sentido e valor a partir do que Rancière (2009) chamou de "regimes de visibilidade das artes": sistemas de enunciação que configuram as condições históricas da existência, circulação e reconhecimento das práticas, discursos e objetos da arte no campo social.

Discípulo de Bernd e Hilla Becher, Andreas Gursky é atualmente um dos fotógrafos mais bem-sucedidos de sua geração. Suas imagens em grande formato são das mais caras e cobiçadas em galerias e leilões de arte. Como veremos, as relações entre seu reconhecimento como artista e as condições de valoração de seu trabalho se inscrevem em algumas das faces da problemática que envolve a fotografia: o redimensionamento da experiência do fotográfico

1 Sistematizada por Bruno Latour, a Teoria do Ator-Rede (TAR) é uma forma de abordar os fenômenos sociais no processo de sua fabricação. Na TAR, pessoas e coisas são simetricamente consideradas "atores" (um site, um livro, uma imagem, um museu, um discurso, um procedimento, tanto quanto um artista, um curador, um historiador da arte, por exemplo). Nesta perspectiva, ao "seguir atores" para entender as dinâmicas em que se inscrevem e seus efeitos, o próprio pesquisador se inclui na trama que descreve, assumindo seu papel no processo de construção do conhecimento do qual faz parte, rompendo com a dicotomia sujeito-objeto na pesquisa. A narrativa em primeira pessoa, como veremos ao longo deste texto, é coerente com a TAR, que lança mão da observação participante e da descrição densa da etnografia. A escritura em primeira pessoa faz parte precisamente das estratégias discursivas do relato etnográfico e afirma a inclusão da experiência do pesquisador no processo da pesquisa com a intenção de trazer esse vivido para as próprias descrições e análises. Neste texto, o uso da primeira pessoa ajuda, por exemplo, a contextualizar o encontro do autor com a imagem que gerou este artigo, que se deu a partir da observação de fatos e situações ocorridos na internet e do contato direto com eventos de arte. Com isso, a experiência direta do pesquisador se torna parte do processo de rastreio das redes de relações multi-situadas que envolvem a obra e sua visibilidade no mercado de arte e cujas dinâmicas são descritas e analisadas aqui. 
e do estatuto da representação na imagem e as mudanças nas funções e nos modos de produção, circulação e legitimação da fotografia na atualidade.

\section{Rastreando um sucesso}

Em novembro de 2013, um amigo fotógrafo postou no Facebook um link para uma nota publicada no portal de notícias G1 com o título "Foto mais cara do mundo é vendida por quatro milhões e trezentos mil de dólares, em Nova York". Rhein II (FIG. 1) foi vendida em 2011 na Christie's, uma das mais importantes casas de leilão do mundo, e batera o já fabuloso preço alcançado meses antes por Untitled \#96 (1981), da artista americana Cindy Sherman, pelo valor de três milhões e novecentos mil dólares².

Figura 1- Rhein II (1999)

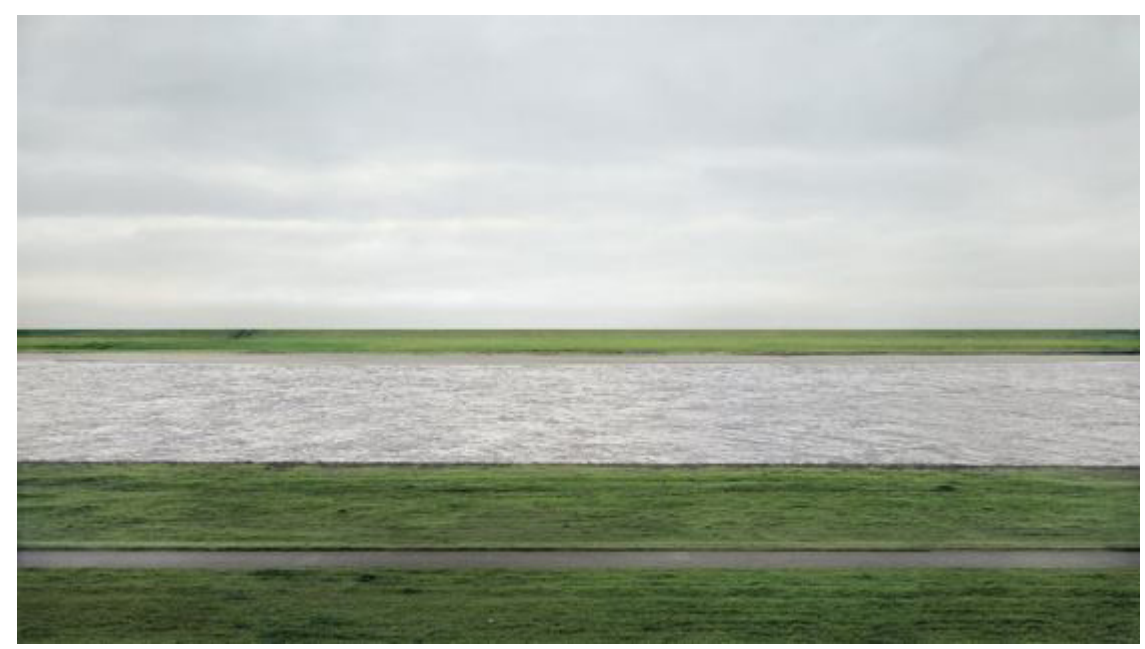

Fonte: Galassi, 2001.

Rhein II apresenta uma vista de um trecho do Rio Reno e foi digitalmente manipulada pelo artista para apagar todo vestígio de pessoas ou objetos originalmente presentes na cena. Formada basicamente por faixas paralelas verdes e cinzas, Rhein I/ é uma imagem conceitual que dialoga com aspectos simbólicos associados ao Reno e com referências da história da arte ${ }^{3}$, frustrando inicialmente a expectativa de grandiosidade e complexidade esperada por uma obra tão valorizada. Este é o fato que chamou minha atenção ao ver pela primeira vez Rhein I/ no Facebook e na experiência de observação que acabou

2 O trabalho de Sherman, por sua vez, havia desbancado 99 Cent II Ditychon, de Gursky, vendida em 2006 por quase três milhões e meio de dólares, e que vinha sendo considerada até 2011 a foto mais cara do mundo.

3 As paisagens do Reno influenciaram fortemente as produções literária e musical europeias e se incorporaram principalmente na cultura alemã. Rhein I/ vincula-se a esse campo de referências e também a um tipo de visualidade que remete à pintura abstrata e à arte conceitual dos anos 60 e 70. 
se produzindo a partir do rastreio dos vetores implicados nas controvérsias envolvendo a foto. São tais controvérsias que constituem aqui o ponto de partida para a discussão sobre o estatuto da fotografia e da representação no campo da arte e da construção de seu valor e sentido enquanto obra.

Através de um trabalho de observação participante em galerias e feiras de arte contemporânea como ArtRio e SPArte, eu percebera que os preços alcançados pela fotografia no exterior e no Brasil eram consideráveis, equiparando-se - e não raro superando - os de pinturas, esculturas, vídeos e instalações. Na ArtRio, por exemplo, tendo acompanhado desde 2013 diferentes trabalhos de artistas representados pelas principais galerias nacionais e estrangeiras, me surpreendi com o preço de trabalhos como os de Candida Hoffer, também discípula dos Becher e da mesma geração de Gursky, vendido por US\$147.0004. Mesmo diante desses valores, como não se sentir interpelado pela a cifra alcançada pela foto de Gursky?

Talvez a história pudesse ser explicada simplesmente como questão de marketing ou pela bolha especulativa criada no mercado de arte a partir de 2009, com a crise econômica mundial que movimentou quase 60 bilhões de dólares em 2012 (Quoi, 2013). Obras de arte podem ser vistas hoje como commodities e alguns artistas são efetivamente figuras integradas a um star system. Mas seria apenas essa a questão? Afinal, por que Gursky? E por que esta foto em particular?

Gursky é reconhecido no mundo da arte contemporânea com um "fotógrafo de paisagens". Mas, observando suas imagens, tive a impressão de que, apesar de "reais", suas paisagens eram "inventadas" pelo trabalho que realizava com os elementos registrados. O documento parecia ser o ponto de partida para suas criações, não o de chegada. De certa forma, esta observação corresponde ao que o crítico Rupert Pfab (1998) havia escrito sobre Gursky: "o principal interesse de Andreas Gurksy não é o objeto que ele está fotografando, mas sim o ato de transformar a sua experiência especificamente visual em uma imagem" (Pfab in Syring, 1998, p. 9). Para Pfab, a obra de Gursky reflete "as formas de arte e da estética do cotidiano da sociedade do século 20" e muitas de suas imagens seriam "alegorias que oferecem uma crítica cultural do papel do homem no composto natureza, tecnologia, arte e sociedade" (Pfab in Syring, 1998, p. 9).

Na mesma linha argumentativa, a curadora britânica Charlotte Cotton (2009), observando os aspectos humanos e sociais dessas "paisagens", vê seus trabalhos como um "mapeamento da vida contemporânea governada por

4 O preço médio dos trabalhos em fotografia na ArtRio em 2013 e 2014 girava em torno dos $\mathrm{R} \$ 30.000$, podendo chegar a mais de $\mathrm{R} \$ 500.000$. (Pesquisa do autor) 
forças que não se podem ver enquanto permanecem em meio à massa humana" (Cotton, 2009, p. 84). Um exemplo disso seria trabalhos como Chicago Board of Trade (1999) (FIG. 2).

- Figura 2 - Chicago Board of Trade (1999)

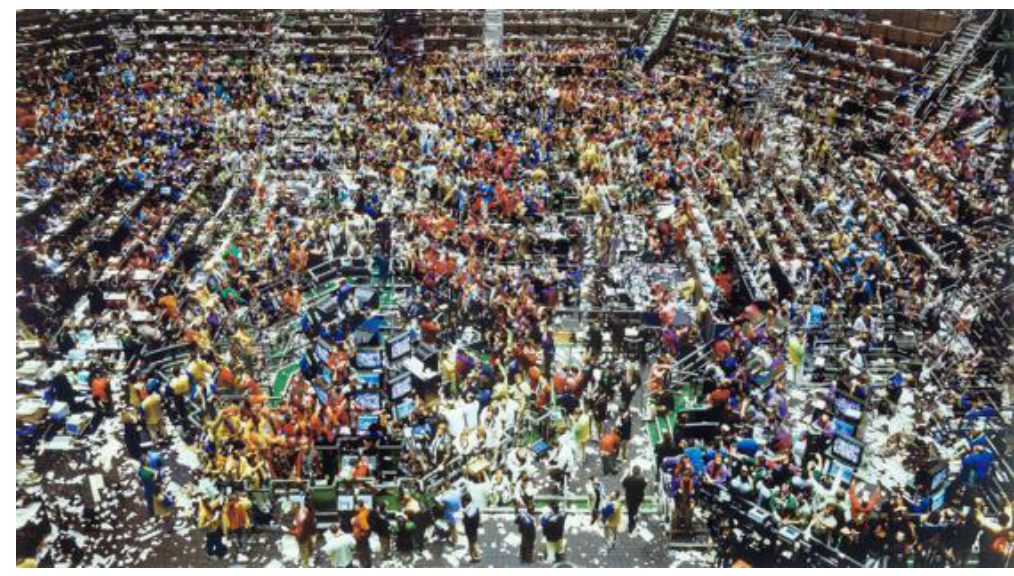

Fonte: Galassi, 2001.

Nele veríamos, por exemplo, como o artista transformaria uma situação concreta em formas visuais formadas por pontos e cores a partir de um ponto de vista à distância e do alto. Esse tipo de procedimento - que transforma uma cena em uma imagem quase abstrata e em uma circunstância visual que nos impede de reconhecer de imediato o que se vê - deslocaria nosso olhar de uma abordagem da imagem enquanto "conteúdo" a ser transmitido e nos levaria a percebê-la como campo de tensão ou como "narrativa", no sentido em que a entende por Paul Ricoeur (1994): como modo de configuração das ações humanas e de sua regulação por operações de representação.

Esses e outros modos de perceber e analisar a fotografia de Gursky remetem a um grande debate que vem sendo realizado a partir dos anos 90 por artistas, curadores, críticos e pesquisadores de história da arte e que sugere que o interesse da fotografia na arte contemporânea não estaria em "narrar o real", mas apresentá-lo à nossa percepção e ao nosso pensamento como uma construção narrativa. Este debate aponta, finalmente, para o que se propõe como um outro entendimento para as questões do documento, da narrativa e da representação na atualidade, como veremos mais adiante.

Contudo, mesmo imerso como pesquisador em tais questões, tendo pesquisado sobre Gursky e sobre as questões envolvendo seu trabalho e testemunhado a monumentalidade de suas imagens, o fato é que o valor obtido com a venda de Rhein I/ me indignou tanto quanto me instigou. Foi então que resolvi procurar mais informações sobre o leilão na internet. Entre notas de outros 
portais de notícias que praticamente reproduziam as mesmas informações do G1 sobre a venda, topei com dois fóruns "leigos" de discussão on-line onde a notícia fora reverberar à época: bannination.com e bike chatforums.com. Em bannination.com, a questão rendeu comentários durante dois dias, alguns dos quais reproduzo aqui : "essa é, sem dúvida, a foto mais chata do mundo"; "que se dane essa porcaria, isso vale mais que Anselm Adams?"; e "Rhein I era melhor". Um texto sobre Rhein // foi reproduzido na íntegra e alguém satiriza: "(...) tradução: é uma bela foto"; "com o dinheiro que economizei com a compra da imagem agora posso comprar US\$ 4,3 milhões de bilhetes de loteria". Alguém então posta uma pintura de Rothko e inicia-se uma discussão sobre arte, com direito a citações de historiadores e críticos, ao que alguém replica: "pode citar a teoria de arte que você quiser, a foto é uma chatice!". Mais ao final, alguém arrisca: "é arte moderna, tem a ver com contexto e metanarrativa".

No bikechatforums.com, a discussão rendeu um dia. O primeiro comentário lançava um link para a nota da BBC sobre o leilão. Comentários irônicos também se repetiam: "como a maior parte da arte moderna, isso é uma bobagem"; "minha sobrinha poderia ter tirado essa foto com uma câmera descartável. Ela tem quatro anos"; “(...) eles dizem tantas palavras sobre absolutamente nada (....), mas em última análise é bobagem expandida que tem pouca serventia a não ser para dar a ilusão de que eles pensaram em alguma coisa"6.

Os comentários, as referências à "arte" e a seus "especialistas" me interpelaram de forma decisiva. Um abismo pareceu abrir-se entre Pfab e Cotton e os participantes dos chats opondo de um lado "especialistas" e "pessoas comuns", o que é "sério" e o que é "bobagem". Porém, o que mais me chamou a atenção não foi a oposição entre as partes ou suas razões, mas perceber como essa disputa pelos sentidos implicava em um trabalho de fabricação dos fatos, nos quais são definidas partes comuns e partes exclusivas. De toda forma, foi surfando na onda dos "excluídos" que me deparei com uma nova pista.

\section{A construção de um conceito e de um valor artísticos}

Depois de reler algumas vezes os posts em bannination.com, reparei que logo no topo de um dos comentários onde fora reproduzido o texto sobre Rhein

5 Tradução do original: "No doubt this is the most boring picture in the world"; "To hell with this crap. Is it worth more than Anselm Adams?"; "Rhein I was better"; “(...) In other words: it's a beautiful photo"; "With the money I saved I can now buy US $\$ 4.3$ million lottery tickets." "You can quote the art theory you want, the picture is boring shit." "This is modern art, it has to do with context and metanarrative."

6 Tradução do original: "Just like most modern art, its a load of shit"; "My niece could take that photo with a disposable camera. She's 4"; "[...] They say so many words about absolutely nothing [...], but ultimately it's expanded drivel that serves little purpose other than to give the illusion that they've thought about something". 
II havia um link: "From the auction lot notes"7. Cliquei e fui parar na página da venda de Rhein // no site da Christie's.

Na página, me deparei com uma série de informações padronizadas sobre a obra de Gursky e sobre outras obras que faziam parte do lote. Nome e imagem da obra (que pode ser aumentada num clic) figuram na parte superior da página, à esquerda. Ao lado da imagem da obra veem-se informações sobre o local da venda, preço estimado (correspondendo ao lance inicial) e preço final alcançado pela obra -dados que podem ser compartilhados, impressos e/ou enviados por e-mail.

$\mathrm{Na}$ parte direita da página encontram-se links para as demais obras integrantes daquele lote, dispostos em pequenos blocos compostos por uma pequena imagem das obras, nome e data de nascimento do artista, título e preço. Ali desfilavam pinturas e esculturas de artistas como De Kooning, Donald Judd, Eva Hesse, Richard Prince, Jeff Koons e Basquiat, cujos preços partiam quase todos da casa de um milhão de dólares. Não havia outra obra fotográfica, embora alguns dos artistas ali elencados trabalhassem também com fotografia, como Prince. Nesse lote, a obra de Gursky alcançara o mesmo preço do trabalho de Basquiat (anos 70) e ultrapassara por pouco o do artista contemporâneo Jeff Koons e por muito o da obra de Eva Hesse e de Donald Judd, artistas conceituais dos anos 60.

Logo abaixo da imagem da obra existem três abas: uma geral, de "descrição do lote", com a ficha técnica da obra - nome do artista, data de produção, formato e dimensão, número de edições (tiragens), museus em cujas coleções estão as outras edições, proveniência (galeria onde foi adquirida pelo atual colecionador), indicações de publicações especializadas onde a obra aparece e locais onde a obra já foi exposta. É onde tomamos conhecimento de que Rhein /l pertencia a um importante colecionador alemão e era a impressão número um de uma tiragem de seis exemplares ${ }^{8}$ e que, destes, ela era a maior de todas: quase dois metros de largura por três e meio de comprimento. É também nesta seção que se pode conferir o invejável currículo de Rhein Il: suas outras tiragens fazem parte das coleções do MOMA, em Nova York, da Pinakothek der Moderne, em Munique, da Tate Modern, em Londres, e da Glenstone Collection, em Potomac, Estados Unidos. Rhein II também já foi exposta em Munique,

7 Das notas sobre o lote no leilão. Tradução do autor.

8 O número de edições tem um significado particular na valoração das obras fotográficas: do ponto de vista da produção, juntamente com a dimensão, o acabamento e o tipo de papel, a tiragem é um dos fatores que influenciam no valor de um trabalho. Quanto menos reproduções ele tiver, mais vale. 
na Haus der Kunst; no Istambul Modern; no Sharjah Art Museum; na Ekaterina Foundation, em Moscou; além de Melbourne, na National Gallery of Victoria; e em Kiev, na Pinchuk Art Center.

A segunda aba traz as mencionadas "notas sobre o lote". Como veremos mais adiante, trata-se de um texto que apresenta a obra e o artista juntamente com referências e citações a artigos e textos curatoriais. Finalmente, a terceira aba da página de venda de Rhein // traz links relacionados à obra e um podcast do diretor do departamento de "arte contemporânea e europeia do pós-guerra" da Christie's, chancelando institucionalmente a obra com sua marca.

Ao observar essa pletora de informações tão cuidadosamente organizada e elegantemente apresentada no site, tive a impressão de me deparar com uma espécie de mapa do "sistema das artes", cujos elementos se estendiam por um amplo aparato que participava da construção da visibilidade da produção artística contemporânea, ao mesmo tempo em que lhe conferia valor e sentido. Também foi impossível não perceber como esse aparato construía sua realidade de mercadoria. Mas essa visibilidade, que em parte ocorre pelo modo de apresentação da obra como produto no interior dos processos de circulação e legitimação, não é produzida apenas dentro do próprio mercado de arte. Ela se dá apoiada, como veremos, nas relações com o discurso curatorial e com a história da arte, que servem também como critérios para a seleção de projetos e obras para editais, exposições em centros culturais, museus, galerias, salões e aquisição de acervo, por exemplo.

Em todo caso, quando penso que a ideia que fazemos da arte e de seus objetos e do tipo de relação com o mundo que ela nos dá a ver é e sempre foi construída por essas cadeias de mediações, lembro dos comentários sobre a venda de Rhein I/ nos chats da internet. A questão que mais chamou minha atenção ali não tinha sido tanto a crítica em si ao valor alcançado pela obra de Gursky, mas o modo como os comentários reagem à ideia de que: 1) Rhein /l seja arte; 2) tal fotografia, que não convenceria enquanto tal, possa valer mais que outra obra (e particularmente cerca de quatro milhões de dólares); 3) os discursos que tentam justificá-lo não passariam de retórica vazia. Ou seja, a visão de que a arte contemporânea se apoiaria mais nas intrincadas cadeias de produção de valor do que nas próprias obras ou de que seus critérios seriam obscuros ou apenas para iniciados - o que a rigor não é uma inverdade - também contribui para a ideia que fazemos da "Arte Contemporânea" como algo "hermético" ou "sem sentido", para não dizer uma "falácia". Os fatos fabricados e dados a ver no sistema das artes - mercado, circuito expositivo e academia - forjam e projetam para a arte e seus objetos uma "realidade" que servirá de referência para o 
entendimento do espectador e para o balizamento de sua percepção sobre a obra e para os modos como ela media nossas relações com o mundo.

Isso apenas evidencia uma constatação já antiga nas ciências sociais: a ideia de que na arte, tanto quanto em outros campos da vida social, práticas e discursos são organizados por uma rede de relações. Niklas Luhman (2000), provavelmente na esteira da sociologia da arte de Bourdieu (1996), foi talvez um dos primeiros pesquisadores da comunicação a estudar a arte como "sistema social". Luhman vê o funcionamento da arte interconectado com outros domínios, como a ciência, a economia e a política. Seria por meio das relações com esses outros campos que a arte se individuaria e se diferenciaria deles.

Também na história da arte alguns autores se interessam pelo aspecto do "sistema social" da arte através do estudo de suas instituições. Essa perspectiva concorre, como as de Bourdieu e de Luhman, para a desconstrução da suposta autonomia da arte. Para Oliveira e Couto, por exemplo, nem a obra de arte é autônoma e existe no vazio, nem a criação artística é gratuita:"(...) de algum modo a produção artística está atrelada ao contexto cultural em que se insere, dentro de uma comunidade de sentidos em constante modificação" (Oliveira e Couto, 2012 , p. 7). É que a arte não é e nem nunca foi uma atividade desinteressada e uma esfera separada do social, mas uma instância com funcionamentos e regras de produção, legitimação e visibilidade como qualquer outra.

Não por acaso, em suas investigações sobre as relações entre estética e política, Rancière (2009) vai considerar, por exemplo, as práticas artísticas como "modos de fazer" circunstanciados histórica e culturalmente. Para ele, as práticas artísticas e as das instituições da arte são práticas sociais que falam dessas lógicas de organização dos modos de ser da arte e de seus objetos num certo momento e as quais ele chamou de regimes de visibilidade das artes: "tipo específico de ligação entre modos de produção das obras ou das práticas, formas de visibilidade dessas práticas e modos de conceituação destas e daquelas" (Rancière, 2009, p. 28).

Esses regimes, por sua vez, promovem o que ele chamou de uma "partilha do sensível": "sistema de evidências sensíveis que revela, ao mesmo tempo, a existência de um comum e dos recortes que nele definem lugares e partes respectivas" (Rancière, 2009, p. 15). É esta noção de partilha que me permite vincular aqui o pensamento de Rancière ao de Latour. $\mathrm{O}$ ato de fazer e mostrar arte se inscreve numa rede de relações onde atuam atores diversos: obras, artistas, curadores, colecionadores, mídia, público, leis de incentivo, museus, academia, galerias, feiras e leilões. Essas redes nos informam sobre o funcionamento dos regimes que organizam discursos, práticas e visões de mundo relativas aos modos de existência da arte e seus objetos, que, por sua 
vez, participam ativamente da organização de nossa experiência sensível. No caso de Rhein II, identificação, reconhecimento, legitimação e "rankeamento" de obras e artistas e a aquisição de credenciais para circular, além de ser visto e adquirido de forma exclusiva, são algumas das figuras das relações entre visível e dizível no sistema das artes, do qual Rhein I/ e a Christie's fazem parte.

\section{A construção do sentido e do valor material de um objeto de arte}

Foi isso o que vi no site da Christie's e o que ele me pareceu enunciar, com seus dados sobre a proveniência das obras, os locais onde haviam sido adquiridas e expostas, referências bibliográficas sobre artista e obra e textos curatoriais. Todos esses elementos participam da produção de sentido dos objetos da arte, através de arranjos particulares que possibilitam uma imagem tornada "obra" transformar-se também em commodity de luxo. Graças a esses elementos e a seu trabalho de mediação (Latour, 2012), é possível envolver a obra em diversas camadas que constroem sua realidade de objeto artístico e de produto (Morais, 2014), dotando ambos de um valor estético que justifica o lugar que ocupa no olimpo dos lotes de elevado significado artístico, históricocultural e material.

Cada dado e cada link do site, articulados entre si, permitem entrever as "partilhas" que a um só tempo organizam e hierarquizam os modos de fazer e de mostrar do mercado da arte e desfiar a lógica de equacionamento dos variáveis componentes do valor de uma obra. É assim que, formando um amálgama, esses elementos e os arranjos que eles estabelecem promovem a construção de: 1) o valor de um nome (artista) - dado pelo lugar que ocupa no sistema das artes, por sua liquidez e pela "qualidade" do trabalho; 2) a "qualidade" do trabalho avaliada em parte pelos critérios vigentes no campo da arte referenciados pela academia e pela crítica, pelo lugar que ocupa na história da arte, mas também pelo nome e a posição do artista no mercado e pela sua relação com outras obras e com outros artistas; 3 ) a liquidez da obra - dada pelas relações entre o nome do artista e a "qualidade" do trabalho, o grau e tipo de inserção no mercado e sua posição na história da arte e em relação a outros artistas e obras.

O que o site da Christie's encarna é a rede que constrói o valor da obra e do artista através de diversos atores e cujo papel não é definido apenas pela Christie's, mas pelo lugar que esses vetores assumem no sistema das artes e no qual a Christie's e seu site são importantes mediadores. Mas, como vimos, essa construção só se torna possível porque os dados sobre a obra e sobre sua relação com outras obras e artistas trabalham e são trabalhados por elementos pertencentes a outras redes, conectadas no espaço do site. Neste, também 
chama a atenção a relação entre obras leiloadas pela Christie's e a indicação de revistas especializadas e catálogos de exposição onde a obra figura.

No caso da relação com outros trabalhos e artistas, foi possível perceber no site que os trabalhos mais valorizados em fotografia eram os de Gursky, Cindy Sherman e Jeff Wall, nesta ordem. Essa relação entre obras e artistas tem o efeito de elevar o valor pelo patamar alcançado pelas vendas de trabalhos anteriores, que torna-se um novo parâmetro para os preços de partida. Dessa forma, posicionar Gursky entre outros artistas renomados num mesmo lote, como vimos na descrição da página de Rhein // no site da Christie's, e posicionálo entre outros artistas fotógrafos em particular, estabelecendo uma espécie de ranking entre eles, é um fator importante não apenas para a liquidez da obra, mas também para a legitimação de seu valor artístico.

Mas valores monetário e artístico da obra não se sustentam apenas por rankeamento, pela lei da oferta e da procura ou pela posição que ocupa entre outras obras. Também é necessária a mobilização de outros agentes que ajudem a balizar o valor da obra em outros termos: a partir do lugar que ocupa na história da arte. É quando entra o uso do discurso curatorial no texto de apresentação organizado pela Christie's na página do lote do qual fazia parte Rhein II.

O texto foi elaborado pelos especialistas do departamento de informação do setor de arte contemporânea e do pós-guerra da Christie's (2011) e lança mão de referências à história da arte e a artigos publicados sobre Gursky e sua obra. Estes são elementos igualmente importantes que a Christie's mobiliza para legitimar a posição da obra e do artista. Por um lado, o lugar ocupado por artista e obra configura e regula noções como autoria, originalidade e valor material dos trabalhos. Por outro, isso não ocorre desvinculado de um outro conjunto circunstanciado de práticas discursivas e não-discursivas, que autorizam determinadas formas de ser da arte e de seus objetos e participam da fabricação de seu valor e sentido como obra. A questão aqui parece ser, portanto, menos a invenção arbitrária de um valor/sentido e mais perceber o quanto apreciação, qualificação e posicionamento são também alvos do investimento de diferentes atores, como o discurso curatorial.

As "notas sobre o lote" compilam e articulam uma série de informações sobre Gursky e sobre Rhein II - alvo dos comentários mais ácidos dos membros de banninatiom.com e bike chat forums -, apontando exatamente para a apropriação e o uso intencionado feito pela Christie's da história da arte e do discurso curatorial como parte das ações usadas para posicionar e justificar seu valor no lote. O texto começa com um trecho de uma citação retirada do 
texto de Peter Galassi ${ }^{9}$ no catálogo da exposição de Gursky em Nova York, em 1998, num momento em que Galassi fala diretamente da obra. Na sequência, reproduz parte de um depoimento de Gursky sobre sua fascinação pelo Reno e sobre o processo criativo do trabalho.

A narrativa prossegue com um discurso grandiloquente sobre Rhein II, invocando o significado do Reno na história da arte, elencando propriedades visuais do trabalho e descrevendo seus aspectos formais e plásticos, vinculandoos à tradição da pintura abstrata, ao minimalismo e à questão do sublime:

[...] Como Peter Galassi observou, com seus arranjos horizontais e geométricos livres de cor, Rhein II reflete uma "rica herança da estética minimalista de Friedrich a Newman e de Richter a Donald Judd" (P. Galassi, "O Mundo de Gursky," em Andreas Gursky, Nova lorque, 2001, p. 35). Na verdade, os traços de cada um desses antepassados são visíveis no trabalho: celebração de Caspar David Friedrich aberto de horizonte infinito de Deus; subversão lúdica de Gerhard Richter da paisagem romântica; e reflexões serializadas de Donald Judd sobre as qualidades da sociedade industrializada e invocação de Barnett Newman do "sublime" através da abstração (Christie's, 2011, s/p). ${ }^{10}$

A esses aspectos, o texto adiciona uma referência ao lugar ocupado por Gursky na história da fotografia, particularmente na tradição da fotografia documental, secundada por um trecho do texto de Ralph Pfab, na intenção de situá-lo em relação à arte contemporânea e à discussão que esta faz da fotografia:

\begin{abstract}
Gursky foi originalmente educado pelos célebres artistas Bernd e Hilla Becher, na famosa Künstacademie em Düsseldorf. Com a perspectiva direta e inabalável centrada em um tema, no caso, o trecho reto e familiar do rio Reno, seu estilo lembra a própria prática distintiva dos Becher. No entanto, seu trabalho faz uma ruptura radical com o seu brilhante uso de cores e imagens de grande formato. De fato, confrontado com o que ele considerava ser as insuficiências fundamentais da prática documental, Gursky se convenceu em 1992 a começar a usar a tecnologia digital como um meio de manipulação.
\end{abstract}

9 Então diretor da área de Fotografia do MOMA de Nova York e curador da exposição retrospectiva de Gursky neste museu.

10 Tradução do original: "[...] As Peter Galassi has noted, with its unimpeded horizontal and geometric arrangements of color, Rhein II reflects a "rich inheritance of reductive aesthetics from Friedrich to Newman to Richter to Donald Judd" (P. Galassi, "Gursky's World," in Andreas Gursky, New York, 2001, p. 35). Indeed, traces of each of these forebears are visible in the work: Caspar David Friedrich's open celebration of God's infinite horizon; Gerhard Richter's playful subversion of the romantic landscape; Donald Judd's serialized reflections on the qualities of industrialized society; and Barnett Newman's invocation of the "sublime" through abstraction". 
Ao fazê-lo, o artista habilmente gerou uma "ilusão de uma realidade fictícia", pondo em questão a veracidade da imagem, na medida em que ela oscila entre uma paisagem intocada e um reenquadramento artificial do mundo (Christie's, 2011, s/p). ${ }^{11}$

Finalmente, o texto associa Rhein II ao conjunto da obra de Gursky, especialmente à sua fase mais recente, como a desejar evidenciar a coerência de sua linguagem em outros trabalhos, que, mesmo abordando temáticas diferentes, guardariam igualmente um certo aspecto de geometrização e abstração com os quais o artista constrói suas paisagens. As obras invocadas nesse momento são 99 Cent, de $1999^{12}$ (FIG. 3) e Paris, Montparnasse, de 1993 (FIG. 4).

- Figura 3 - 99 Cent (1999)

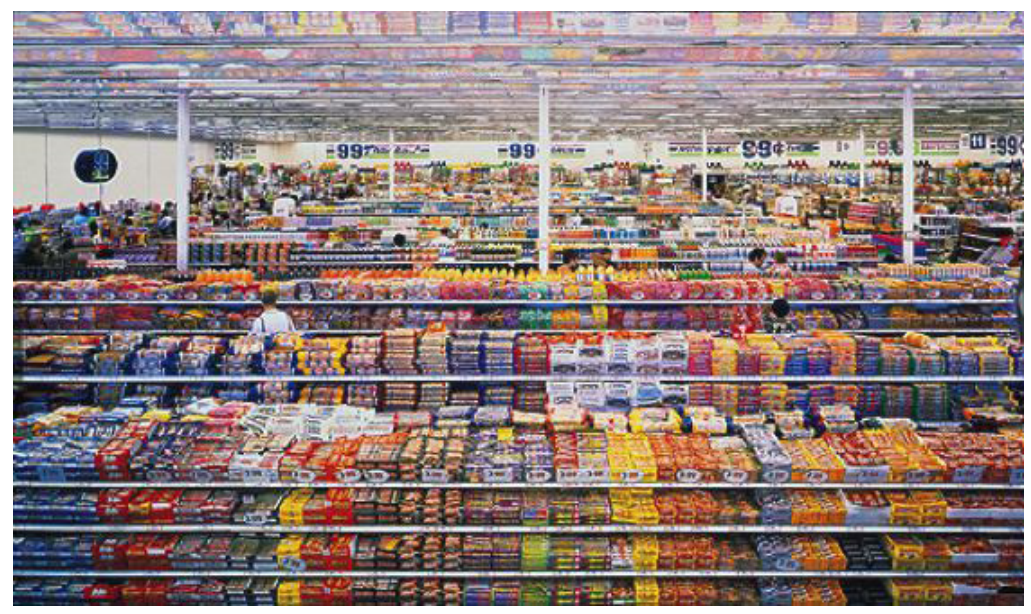

Fonte: Galassi, 2001.

11 Tradução do original: "Gursky was originally schooled by the celebrated artists Bernd and Hilla Becher at the renowned Künstacademie in Düsseldorf. With his direct and unflinching perspective centered upon one theme, here the familiar straight stretch of the river Rhine, his style recalls the Bechers' own distinctive practice. However, his work does make a radical departure with its brilliant use of color and large-format imagery. Indeed, faced with what he considered to be the fundamental inadequacies of the documentary practice, Gursky was persuaded in 1992 to begin using digital technology as a means of manipulation. In doing so, the artist skillfully generated an "illusion of a fictitious reality," throwing into question the veracity of the image as it fluctuates between a pristine landscape and an artificial reframing of the world [...]".

12 Considerada a fotografia mais cara do mundo, antes de Untitled \#96 de Cindy Sherman desbancála, em 2011. 
Figura 4 - Paris, Montparnasse (1993)

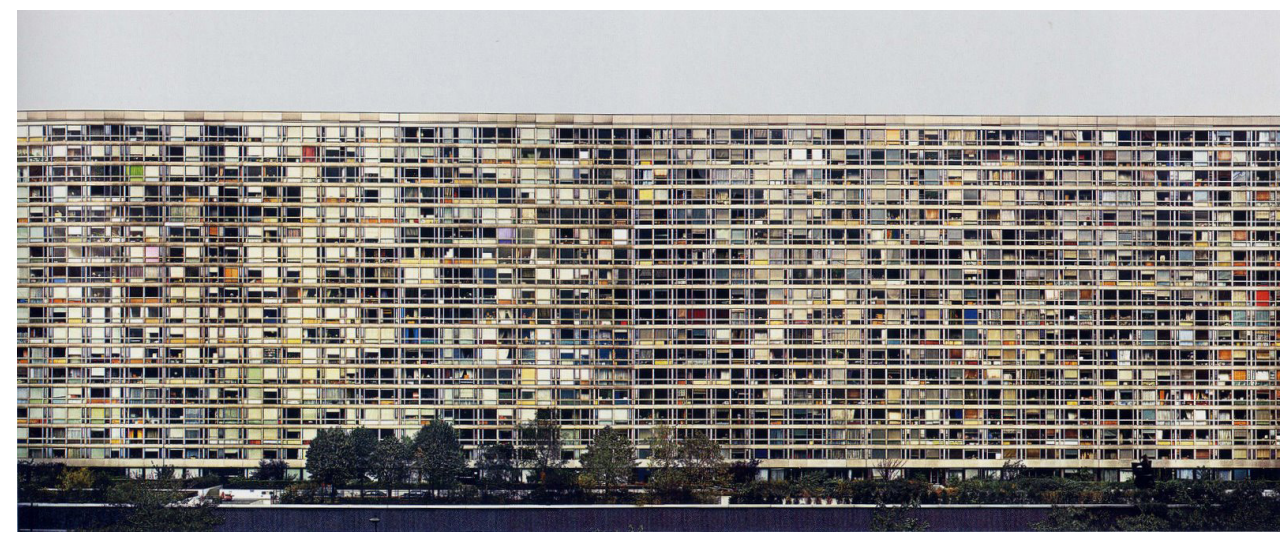

Fonte: C4 Contemporary Art.

Essa visão de conjunto - que apresenta os processos pelos quais se forjaria uma imagem do artista e de sua obra - não deixa certamente de constituir uma narrativa, no sentido ricoeuriano. Mas o que chamou minha atenção no texto foi o modo como essa narrativa é montada pela Christie's. A seleção e uso de determinados trechos e referências cria parâmetros de julgamento e de valoração da obra. Ou seja, são uma forma de construir e de legitimar a "qualidade do trabalho" de Gursky e, ao mesmo tempo, de conferir valor ao artista e liquidez à sua obra.

Contudo, mesmo esses arranjos narrativos não parecem ser suficientes para justificar o destaque que trabalhos de fotografia como os de Gursky, Cindy Sherman, e Jeff Wall, entre tantos outros, alcançam hoje na arte. Fatores relativos ao próprio campo da fotografia precisam ser combinados a essas operações de produção de sentido. É o que veremos a seguir.

\section{A fotografia na arte como questão de comunicação}

Ao trazer a questão da foto milionária de Gursky, busquei levantar uma das questões que interessam a uma pesquisa iniciada em 2012, em fase de conclusão, sobre os processos de individuação da fotografia contemporânea na arte. Por individuação entendo o processo de diferenciação que configuraria a experiência contemporânea da fotografia enquanto algo supostamente dotado de uma experiência "própria", algo que nela definiria particularmente o que é (ou não) visível e dizível, influenciando, portanto, nossas relações com as coisas do mundo.

Apesar de disfrutar há tempos - pelo menos desde Benjamin, Barthes, Flusser e Sontag - de um status de objeto técnico, teórico e estético, teria sido 
apenas com a arte conceitual que a fotografia teria passado a ser legitimada como "objeto artístico" (Poivert, 2010; Fried, 2012). A maior parte dos discursos das teorias e da história da arte apontam para o fato de que somente a partir daquele momento teria sido possível perceber com mais clareza mudanças que envolvem: 1) o que eram consideradas novas condições da experiência do fotográfico; 2) os modos de produção e apreciação das imagens - notadamente as da arte, mas também as midiáticas; e 3) os valores e as funções atribuídos à imagem documental em diferentes contextos.

Por isso, o caso de Rhein II interessa aqui não apenas do ponto de vista da arte, mas também como fato inscrito nos processos de produção artística atual e nas redes que constroem sua visibilidade. Uma vez que a visão e as imagens podem ser consideradas como uma forma de organizar nossas relações com o mundo (Maynard, 1997; Didi-Huberman, 2010; Crary, 2012), investigar a construção da visibilidade da fotografia no campo da arte significa investigar como nesse campo se estabelecem para a fotografia suas condições de presença e reconhecimento e como essas condições podem nos ajudar a compreender algumas formas de produção de modos de vida e de visões de mundo na atualidade.

O fato de artistas como Gursky não estarem interessados apenas em registrar e reproduzir eventos e fatos do cotidiano, mas de realizar, a partir deles, uma investigação sobre as relações entre arte e sociedade, arte e vida, arte e suas instituições, seria um sintoma disso. Certamente esse deslocamento não deve servir para justificar por si só a importância e o valor conferido pelo mercado de arte a imagens como Rhein II, mas contribui para lançar um outro olhar sobre as imagens na atualidade e sobre seu estatuto, por evidenciar o quanto a experiência da imagem hoje encontra-se não apenas na produção do documento, mas na produção de sentido e valor para ele (Fontcuberta, 2012).

Esse modo de considerar a imagem me parece crucial hoje para os estudos da imagem e das tecnologias de comunicação. Casos como os da circulação de fotos no Instagram ou de vídeos nas redes sociais, por exemplo, são fenômenos onde o que parece estar em jogo é menos o que as imagens significam e mais os modos como são produzidas e difundidas e o papel de interpelação, agregação e mobilização que assumem no âmbito das interações sociais onde se apresentam e propagam. Esses fenômenos exigem de nós, portanto, uma outra atitude e outras formas de análise das imagens e dos modos como estas atualmente participam de nossos modos de perceber e de estar no mundo. Por isso, aposto nas questões trazidas pela fotografia na arte como sendo pertinentes para a comunicação. Uma dessas questões é a possibilidade de sairmos de uma 
perspectiva tecnicista que atribui juízo de valor ou significado para as imagens e adotarmos uma perspectiva que nos permite observá-las nas dinâmicas que fabricam seus modos de presença e de legitimação no campo social, como no caso de Rhein II.

O que Rhein /l permite observar e discutir são exatamente algumas das mudanças que vêm ocorrendo na fotografia no campo da arte. Tais mudanças colocadas pela fotografia hoje neste campo implicam considerá-la como fenômeno que não se esgota na análise da imagem enquanto conteúdo nem se preocupa apenas com seu significado enquanto representação. Corroborando este argumento, Michel Poivert vai afirmar, por exemplo, que a fotografia contemporânea não mais proporia uma revelação do mundo, mas "a evidência do caráter artificial de sua construção" (Poivert, 2010, p. 225). Apesar de ser historiador da arte e da fotografia, Poivert não faz esse tipo de afirmação mirando exclusivamente o campo da arte. O que lhe interessa é tratar da condição contemporânea da fotografia e perceber o que esta condição nos fala relativamente às mudanças nos modos de visão e da atenção em nossas sociedades, como já apontara também Crary $(2012 ; 2013)$.

Ao falar da fotografia a partir da arte, Poivert o faz por considerar que há quase três décadas a fotografia vem fundado as bases de sua atualidade numa relação de contemporaneidade com a própria arte. Ou seja, que a fotografia teria nas questões da arte um lugar privilegiado, embora não exclusivo, para repensar seu estatuto, suas funções e seu reconhecimento hoje.

\section{Considerações finais}

Como qualquer obra de arte, Rhein /I não é apenas um objeto para contemplação: é, antes de tudo, um objeto híbrido de arte, sociedade, cultura, história, política, economia e comunicação. Mas híbrido não como mistura ou somatório desses elementos, e sim como algo cuja natureza se forja e atualiza constantemente no vinco desses elementos e que, por isso mesmo, ultrapassa a soma de suas partes. Todos esses aspectos estão presentes no fenômeno, mas nenhum isoladamente pode dar a dimensão das nuances dos processos de fabricação do valor e do sentido de Rhein II, pois cada um só faz o que faz na relação que estabelecem um com o outro.

O site da Christie's constitui um microcosmo que se articula com um macrocosmo, permitindo acompanhar em certa medida os movimentos, procedimentos e processamentos diversos, que, imbricados entre si, evidenciam o modo como regras e funcionamentos do mercado de arte estão conectados 
com análises e discursos da história da arte, curadores e acadêmicos e com as mudanças da experiência do fotográfico na atualidade.

O que busquei argumentar é que, no campo da arte, artistas, obras e suas trajetórias, história da arte, instituições, mídia e outros elementos relacionam-se entre si e participam da configuração e modulação das regras para a produção e o consumo de obras num dado momento histórico. Por isso mesmo, não desejo indicar nenhuma relação de determinação ou de causalidade entre esses elementos nessas dinâmicas. Cada elemento está conectado e age fazendo vinco com o outro. Nesse vinco produzem-se fatos, realidades mais ou menos visíveis, ativas e irredutíveis às relações estabelecidas umas com as outras. Portanto, não se trata apenas de uma questão de poder do mercado ou das teorias da arte ou da história da arte como chanceladores discursivos ou da vinculação da trajetória do artista e de sua obra a um contexto. Todos se conjugam para produzir um fato e, ao mesmo tempo, participam enquanto atores de uma dinâmica que tem sua faceta mais visível nos processos de produção de sentido e valor de uma obra de arte.

Meu objetivo aqui foi, sobretudo, propor uma discussão e uma análise do caso de Rhein // sem reduzi-lo a seu aspecto artístico ou político ou discursivo. Esta irredutibilidade é o que estou considerando propriamente uma abordagem "de rede" (Latour, 2012) e que busca evidenciar a importância da fotografia na arte para os estudos da fotografia e da imagem na comunicação. Mas, se no campo da arte, o interesse da fotografia está nos jogos que se podem realizar com a representação e nas reflexões sobre nossos modos de vida em sociedade, seu estatuto "artísticodo pela arte rtistas, imagens feitas por aplicativos de celular s" não pode ser explicado unicamente pelo fato da imagem ser feita por um artista, por estar exposta numa instituição de arte ou por ter um caráter supostamente distintivo de outras imagens consideradas "não-artísticas".

Finalmente, o que me parece importante é evidenciar que tal estatuto contribui para uma maior compreensão da experiência da imagem hoje, ao considerar outros regimes enunciativos em que a imagem não é apenas um texto a ser lido ou um repositório da memória, onde a forma não está submetida ao conteúdo e onde real e ficcional não mais se opõem.

\section{Referências}

C4 - Contemporary art. Los Angeles, [2011]. Profile: Andreas Gursky. Disponível em: < http://c4gallery.com/artist/database/andreas-gursky/andreas-gursky.html>. Acesso em: 17 set. 2015. 
CHRISTIE'S. Andreas Gursky. Nova York, 8 nov. 2011. Disponível em: <http://www. christies.com/lotfinder/photographs/andreas-gursky-rhein-ii-5496716-details. aspx\#top>. Acesso em: 17 set. 2015.

BOURDIEU, Pierre. Regras da arte. São Paulo: Companhia das Letras, 1996.

COTTON, Charlotte. A Fotografia como arte contemporânea. São Paulo: Martins Fontes, 2010.

CRARY, Jonathan. Suspensões da percepção. São Paulo: Cosac Naify, 2013.

. Técnicas do Observador. Rio de Janeiro: Contraponto, 2012.

DIDI-HUBERMAN, G. O que vemos, o que nos olha. Rio de Janeiro: Ed. 34, 2010.

FOTO mais cara do mundo é vendida por US\$ 4,3 milhões, em Nova York. G1, São Paulo, 11 nov. 2011. Disponível em: <http://g1.globo.com/pop-arte/noticia/2011/11/ foto-mais-cara-do-mundo-e-vendida-por-us-43-milhoes-em-nova-york.html>. Acesso em: 17 set. 2015.

FONTCUBERTA, Joan. A câmera de Pandora. Gustavo Gili: Barcelona, 2012.

FRIED, Michael. Why Photography matters as art as never before. $4^{\mathrm{a}} \mathrm{ed}$. New Haven and London: Yale University Press, 2012.

GALASSI, Peter. Andreas Gursky. The Museum of Modern Art, New York, 2001.

LATOUR, Bruno. Reagregando o social. Salvador/Bauru: UDUFBA/EDUSC, 2012.

LE MARCHÉ de l'art pour les nuls. Quoi, Paris, 5 abr. 2013. Disponível em: < http://quoi. info/wp-content/uploads/data art/\#.UvgIRfaA3Sg>. Acesso em: 17 set. 2015.

LUHMAN, Niklas. Art as social system. Stanford, California: Stanford University Press, 2000.

MAYNARD, Patrick. The engine of visualization: thinking through photography. Ithaca: Cornel University Press, 1997.

MORAIS, Angélica. Valorações do transitório. In: COUTO, Ronaldo (Org). O Valor da obra de arte. São Paulo: Metalivros, 2014.

OLIVEIRA, Emerson e COUTO, Maria de Fátima. (Org) Instituições de arte. Porto Alegre: Zouk, 2012.

PFAB, Robert. Perception and Communication: Thoughts on New Motifs by Andreas Gursky. In SYRING, Marie Luise (ed.). Andreas Gursky: Photographs from 1984 to the Present. Düsseldorf: Te Neues Publishing Company, p. 9, 1998.

POIVERT, Michel. La Photographie Contemporaine. Paris: Flammarion, 2010. 
RICOEUR, Paul. Tempo e Narrativa (tomo I). Campinas: Papirus, 1994.

RANCIERE, Jacques. A partilha do sensível. 2ª ed. Rio de Janeiro: Ed. 34, 2009.

Recebido em: 25/11/2015

Aceito em: 9/12/2015

Endereço do autor:

Fernando do Nascimento Gonçalves <goncalvesfernandon@gmail.com>

http://lattes.cnpq.br/4102167348100115

Faculdade de Comunicação Social da Universidade do Estado do Rio de Janeiro (UERJ).

Rua São Francisco Xavier, 524, $10^{\circ}$ andar - Pavilhão João Lyra Filho - Maracanã

20550-900 - Rio de Janeiro - RJ - Brasil 